\title{
PENERAPAN MODEL TGT MELALUI SIMULASI PhET TERHADAP PENINGKATAN PEMAHAMAN SISWA PADA ALAT-ALAT OPTIK
}

\author{
Fajrul Wahdi Ginting ${ }^{1 *}$, Nanda Novita ${ }^{1}$,Yeni Rahmadani ${ }^{2}$ \\ Dosen ${ }^{1}$,Mahasiswa2 Program Studi Pendidikan Fisika, Universitas Malikussaleh \\ *Korespondensi: fajrulwg@unimal.ac.id
}

\begin{abstract}
Abstrak: Penelitian ini bertujuan untuk meningkatkan pemahaman siswa menggunakan media simulasi PhET melalui model Teams Games Tournament. Subjek penelitian ini adalah siswa kelas XI MIA MAN 3 Aceh Utara. Jenis penelitian yang digunakan adalah Quasi Exsperimental Design. Pengumpulan data pemahaman siswa dilakukan menggunakan instrument test yang telah divalidasi dan di uji reabilitas. Rata- rata kemampuan pemahaman siswa dengan menggunakan model pembelajaran Direct Introuction adalah 72,75 , sedangkan rata-rata kemampuan pemahaman siswa dengan menggunakan model pembelajaran TGT melalui simulasi PhET adalah 86,75. Hasil uji hipotesis menggunakan Mann Whitney Test pada posttest kelas kontrol dan eksperimen diperoleh nilai signifikan $0,000<0,05$ maka terdapat peningkatan pemahaman siswa yang signifikan. Kesimpulannya adalah pembelajaran menggunakan model TGT melalui simulasi PhET dapat meningkatkan pemahaman konsep siswa kelas XI pada materi alat-alat optik di MAN 3 Aceh Utara.
\end{abstract}

Kata kunci: alat-alat optik, model TGT, simulasi PhET, peningkatan pemahaman konsep.

\section{IMPLEMENTATION OF TGT MODEL TROUGH PHET SIMULATION ON THE IMPROVEMENT OF STUDENTS 'UNDERSTANDING OF OPTICAL INSTRUMENT}

\begin{abstract}
Abstrak: This study aims to improve students' understanding of using PhET simulation media through the Teams Games Tournament model. The subjects of this study were students of class XI MIA MAN 3 Aceh Utara. The type of research used is Quasi Experimental Design. Students' understanding of data was collected using a validated test instrument and tested for reliability. The average understanding ability of students using the Direct Introuction learning model was 72.75, while the average understanding ability of students using the TGT learning model through the PhET simulation was 86.75. The results of hypothesis testing using the Mann Whitney Test in the control and experimental class posttest obtained a significant value of $0.000<0.05$, so there is a significant increase in student understanding. The conclusion is that learning using the TGT model through the PhET simulation can improve the conceptual understanding of class XI students on the material of optical instruments in MAN 3 Aceh Utara.
\end{abstract}

Keywords: Optical Tools, Tgt Model, Phet Simulation, Increased Understanding Of Concepts.

\section{PENDAHULUAN}

Pendidikan adalah usaha sadar dan terencana untuk mewujudkan suasana belajar dan proses pembelajaran agar peserta didik secara aktif mengembangkan potensi dirinya. Pada kurikulum 13 mempunyai tujuan agar peserta didik memiliki kemampuan yang lebih baik dalam melakukan observasi, bertanya dan berkomunikasi. Berdasarkan kurikulum 2013 aspek pengetahuan tidak menjadi satu-satunya penentu kelulusan siswa, namun lebih mengutamakan pada pemahaman, skill, dan pendidikan berkarakter. Dimana siswa dituntut untuk paham atas materi, aktif dalam proses berdiskusi dan presentasi serta memiliki sopan santun dan sikap disiplin yang tinggi. Sehingga, dalam hal ini pendidikan tidak hanya mengutamakan hasil tetapi proses juga sangat penting dalam membangun pengetahuan siswa. 
Dalam pengimplementasian kurikulum 2013 terdapat lima aktivitas belajar yakni: mengamati, bertanya, melakukan percobaan, melakukan penalaran, dan mengembangkan hasil. Untuk menjelaskan kurikulum 2013 tersebut, dalam belajar harus berdasarkan kenyataan. Untuk menjadikan pembelajaran tampak nyata, media pembelajaran memegang peran penting. (Susilo, 2010) menyatakan bahwa selain guru, bahan ajar, dan metode, keberhasilan pembelajaran juga dipengaruhi oleh media yang digunakan. Selain itu (Musfiqon, 2012) mengatakan bahwa penggunaan media yang relevan mampu menjadikan proses pembelajaran berlangsung efektif dan efisien. Hal ini dikarenakan dalam proses pembelajaran, media tidak hanya mampu berperan sebagai penyalur pesan saja, tetapi juga mampu menggantikan tugas guru dalam penyampaian materi agar pembelajaran tersebut tampak nyata.

Salah satu sekolah di Aceh yang sudah menerapkan kurikulum 2013 adalah MAN 3 Aceh Utara. Sekolah ini merupakan salah satu sekolah favorit di Aceh Utara. Dimana sekolah tersebut sudah mempunyai sarana dan prasarana yang sangat memadai. Dimulai dari perpustakaan, laboratorium, dan ruang kelas serta sarana penunjang lainnya. Seharusnya dengan adanya sarana dan prasarana tersebut, pembelajaran di sekolah tersebut sudah menerapkan teknologi dalam pembelajaran khususnya pembelajaran Fisika. Namun, berdasarkan hasil observasi, penerapan teknologi dalam pembelajaran Fisika masih sangat kurang. Hal ini dapat dilihat dari metode pembelajaran yang digunakan oleh guru MAN 3 Aceh Utara. Berdasarkan wawancara dengan guru Fisika, metode yang digunakan masih merupakan metode ceramah, tanya jawab, diskusi, dan jigsaw. Dimana, dalam penerapan metode tersebut tidak adanya peran komputer sebagai sarana pembelajaran siswa. Seharusnya sekolah tersebut sudah mampu menerapkan teknologi dalam proses pembelajarannya. Penggunaan teknologi dalam proses pembelajaran dapat menunjang proses pembelajaran tersebut.

Perkembangan TIK menjadi potensi yang sangat besar untuk meningkatkan kualitas pendidikan (Choiron, 2013). Seiring dengan pesatnya perkembangan ilmu pengetahuan dan teknologi, media elektronik dapat menjadi solusi dari kendala yang ditemui oleh pendidik dan peserta didik saat melakukan pembelajaran dengan konten materi yang berkarakteristik abstrak. Percobaan yang sulit dilakukan di laboratorium real, yang umumnya disebabkan minimnya alat-alat praktikum yang memadai, dapat dilakukan menggunakan media laboratorium virtual yang dijalankan dengan komputer. Pembelajaran dengan menggunakan komputer dikenal dengan konsep pembelajaran berbasis computer CAI (Computer Assisted Intruction). Pembelajaran berbasis komputer berarti proses pembelajaran yang menggunakan alat bantu dan sumber belajar dengan sistem komputer dalam mencapai tujuan pembelajaran. Penggunaan teknologi informasi dan komunikasi menjadi sebuah cara yang efektif dan efisien dalam menyampaikan informasi. Menurut (Siahaan, 2012) teknologi informasi dan komunikasi memiliki potensi besar untuk meningkatkan kualitas pembelajaran, khususnya dalam menampilkan fenomena Fisika. Menerapkan teknologi ke dalam pembelajaran Fisika maka, siswa akan lebih antusias dalam mengikuti pembelajaran seperti yang kita ketahui siswa sekarang jauh lebih tertarik dengan teknologi dibandingkan dengan ilmu pengetahuan terlebih lagi ilmu Fisika.

Salah satu contoh aplikasi yang dapat membantu pembelajaran Fisika adalah virtual lab yang dikembangkan oleh University of Colorado, yaitu PhET (Physics Education Technology). Didalam $\mathrm{PhET}$ terdapat simulasi yang bersifat teori dan percobaan yang melibatkan pengguna secara aktif. Serta, pengguna dapat memanipulasi kegiatan-kegiatan yang berkaitan dengan eksperimen. Sehingga selain dapat membangun konsep, PhET juga dapat digunakan untuk memunculkan keterampilan proses sains.. Sehingga, dengan kata lain media PhET dapat dimanfaatkan untuk pembelajaran Fisika.

Adapun alasan penulis mengapa menggunakan simulasi PhET adalah karena simulasi PhET merupakan simulasi yang sangat mudah digunakan atau diaplikasikan. Serta simulasi PhET menerapkan konsep Fisika yang ada di kehidupan sehari-hari sehingga nantinya siswa mampu langsung melihat penerapan dari materi atau konsep tersebut. Penggunaan media simulasi PhET juga dimaksudkan agar dapat membantu siswa untuk memahami ketidakjelasan dan kerumitan materi yang sedang dipelajari, sebagai bahan ajar mandiri siswa serta dapat membantu guru menyampaikan hal-hal yang belum tersampaikan. 
Salah satu pembelajaran yang dapat dikolaborasikan dengan media pembelajaran $\mathrm{PhET}$ adalah model pembelajaran TGT (Teams Games Tournament). Model pembelajaran ini merupakan konsep belajar yang mengaitkan materi yang diajarkan dengan masalah yang dihadapi pada kehidupan seharihari. Menurut (jacobsen, D, \& Donald, 2009) dengan menggunakan model TGT, informasi yang dipelajari dapat bertahan lebih lama dan tertransfer lebih baik.

Berdasarkan observasi berupa tes soal materi alat-alat optik kepada siswa/i di MAN 3 Aceh Utara. Hanya beberapa yang bisa menjawab soal dengan benar, seharusnya untuk tingkat soal yang muda siswa mampu menjawab dengan benar. Dari kenyataan tersebut maka, dapat penulis artikan bahwasanya materi alat-alat optik sangat sulit untuk dipahami dan diingat konsepnya. Berdasarkan hasil observasi dengan salah satu guru fisika dikelas XI MAN 3 Aceh Utara bahwa proses pembelajaran guru belum mampu menerapkan alat teknologi. Terlebih lagi penggunaan simulasi PhET dalam proses belajar mengajar.

Oleh karena itu peneliti ingin melakukan sebuah peneilitian yang berjudul "Penerapan Model TGT Melalui Simulasi PhET Terhadap Peningkatan Pemahaman Siswa Pada Konsep Materi Alat-alat Optik Di MAN 3 Aceh Utara Kelas XI". Tujuan dari penelitian ini adalah untuk mengetahui apakah model pembelajaran TGT melalui simulai PhET dapat meningkatkan pemahaman konsep siswa pada materi alat-alat optik kelas XI. Manfaat dari penelitian ini adalah: 1) dapat menjadi alternatif solusi dalam proses pembelajaran fisika melalui penggunaan simulasi $\mathrm{PhET}$ bagi guru; 2) dapat meningkatkan pemahaman siswa melalui simulasi PhET; dan 3) dapat memberikan pengalaman dalam penelitian bagi penulis.

\section{METODE}

Penelitian ini dilaksanakan di MAN 3 Aceh Utara. Bentuk penelitian ini adalah penelitian kuantitatif. Subjek penelitian adalah kelas XI MIA 2 dan XI MIA 3 MAN 3 Aceh Utara semester genap tahun ajaran 2020 dengan jumlah 40 siswa. Penelitian ini dilaksanakan pada tiga pertemuan untuk mencapai selesainya materi. Data hasil penelitian diperoleh dari tes dan LKS (lembar kerja siswa).

Pembelajaran kooperatif tipe TGT (teams games tournament) adalah salah satu tipe atau model pembelajaran kooperatif yang mudah diterapkan, melibatkan seluruh siswa tanpa harus ada perbedaan status. Menurut (Imas \& Kurniasih, 2012),"model pembelajaran TGT adalah salah satu tipe atau metode pembelajaran kooperatif yang mudah di terapkan, melibatkan aktivitas seluruh siswa tanpa harus ada perbedaan status, melibatkan peran siswa sebagai tutor sebaya dan mengandung unsur permainan". Menurut (Kusumandari, 2011) bahwa TGT merupakan salah satu tipe pembelajaran kooperatif yang menempatkan siswa dalam kelompok-kelompok belajar yang beranggotakan 5-6 orang siswa yang memiliki kemampuan jenis kelamin dan suku/ras yang berbeda".

Dengan menerapkan model pembelajaran TGT di kelas diharapkan dapat menghilangkan anggapan siswa tentang Fisika adalah pelajaran yang membosankan. Karena dalam model TGT siswa belajar secara berkelompok, terdapat permainan yang berupa tournament, dan penghargaan untuk kelompok yang memperoleh skor terbanyak. (Sudha \& gading, 2016) mengemukakan bahwa dengan diterapkanya model pembelajaran kooperatif tipe TGT dapat membuat siswa untuk saling berkolaboratif dan memotivasi satu sama lain dengan kemampuan yang berbeda-beda, sehingga siswa dapat lebih tertarik, tidak mudah menyerah dan selalu aktif dalam mengikuti dan menyelesaikan tugasnya dalam proses pembelajaran.

Pembelajaran kooperatif tipe TGT (Teams Games Tournament) (Slavin, 2007) terdiri dari lima langkah, yaitu: penyajian kelas (class presentation), belajar dalam kelompok (teams), permainan (games), pertandingan (tournament), dan penghargaan kelompok (team reognition). Dalam model pembelajaran TGT siswa dibagi dalam beberapa kelompok kecil yang anggota kelompoknya dipilih secara heterogen. Kelompok-kelompok ini akan belajar secara bersama-sama (teams) dan akan melakukan permainan (games) untuk menyelesaikan permasalahan, sedangkan tournament dilaksanakan setelah pembelajaran selesai. 
Menurut Suarjana (Ekocin, 2011) menyatakan model pembelajaran TGT memiliki beberapa kelebihan di antaranya: (a) lebih meningkatkan pencurahan waktu untuk tugas, (b) mengedepankan penerimaan terhadap perbedaan individu, (c) dengan waktu yang sedikit siswa dapat menguasai materi secara mendalam, (d) proses belajar mengajar berlangsung dengan keaktifan dari siswa, (e) motivasi belajar lebih tinggi, serta (f) mendidik siswa untuk berlatih bersosialisasi dengan orang lain.

. Menurut (Hamzah B, 2007) menyatakan bahwa media pembelajaran adalah segala bentuk alat komunikasi yang dapat digunakan untuk menyampaikan informasi dari sumber ke peserta didik yang bertujuan merangsang mereka untuk mengikuti kegiatan pembelajaran.

Menurut Arsyad dalam (Umar, 2013) beberapa peranan media dalam pembelajara, diantarnya sebagai berikut: (1) Memperjelas penyajian pesan dan informasi sehingga dapat memperlancar dan meningkatkan proses dan hasil belajar, (2) meningkatkan dan mengarahkan perhatian anak sehingga dapat menimbulkan motivasi belajar, interaksi yang lebih langsung antara siswa dan lingkungannya, dan kemungkinan siswa untuk belajar sendiri-sendiri sesuai kemampuan dan minatnya, (3) mengatasi keterbatasan indera, ruang, dan waktu, (4) memberi kesamaan pengalaman kepada siswa tentang peristiwa-peristiwa dilingkungan mereka, serta memungkinkan terjadinya interaksi langsung dengan guru, masyarakat, dan lingkungannya misalnya melalui karya wisata, kunjungan-kunjungan ke museum atau kebun binatang.

(Ekawati, Haris, \& Amin, 2017) menyatakan bahwa proyek Physic Education Technology di Universitas Colorado telah mengembangkan serangkaian simulasi yang sangat menguntungkan dalam pengintegrasian teknologi komputer ke dalam pembelejaran. Terdapat lebih dari 50 simulasi berdasarkan penelitian yang telah dilakukan sebelumnya. Simulasi tersebut terdiri dari beberapa topik Fisika, Kimia, bahkan Matematika. Simulasi-simulasi ini mudah didapatkan, dapat dijalankan secara online dengan bantuan koneksi internet maupun dengan cara didownload sehingga dapat dijalankan secara offline.

Simulasi PhET (Physic Education Technology) menekankan hubungan antara fenomena kehidupan nyata dengan ilmu yang mendasari, mendukung pendekatan interaktif dan konstruktivis, memberikan umpan balik, dan menyediakan tempat kerja kreatif (Finkelstein, 2006). Simulasi PhET yang akan peneliti gunakan adalah alat-alat optik. Kelebihan simulasi PhET dapat mengetahui jalannya sinar pada lensa hanya dengan menggeser-geser letak benda dan mengukur panjang lintasan letak benda sehingga dapat langsung mengetahui jarak bayangan dan sifat bayangan.

Menurut (Malik, 2010) mengatakan, "Strategi pembelajaran interaktif model simulasi merupakan strategi yang efektif, karena efektif dalam penggunaan waktu dan efektif dalam meningkatkan prestasi belajar mahasiswa". (Lailiyah, 2009) mengemukakan bahwa pembelajaran dengan menggunakan simulasi lebih efektif dibandingkan pembelajaran dengan demonstrasi dan ceramah.

Tujuan pembuatan dari simulasi PhET (Physic Education Technology) menurut (Ekawati, Haris, \& Amin, 2017) yaitu membantu peserta didik untuk memvisualisasikan konsep secara utuh dan jelas, kemudian menjamin pendidikan yang efektif serta kebergunaan yang berkelanjutan.

Menurut Mauke dalam (Hadiwiyanti, 2015) pemahaman menduduki posisi yang sangat penting dan strategis dalam aktivitas belajar, karena merupakan rekonstruksi makna dari hubungan-hubungan, bukan hanya sekedar proses asimilasi dari pengetahuan yang sudah dimiliki sebelumnya.

Indikator keberhasilan dalam penelitian ini adanya peningkatan pemahaman siswa dalam memahami materi alat-alat optik.

\section{HASIL DAN PEMBAHASAN \\ Hasil}

Hasil pemahaman konsep siswa pada materi alat-alat optik diperoleh dari hasil uji soal pretest dan posttest pada masing-masing kelas yaitu kelas XI MIA 3 sebagai kelas eksperimen dan kelas XI MIA 2 
sebagai kelas kontrol. Adapun data pretest dan posttest yang diperoleh dari hasil penelitian di kelas eksperimen dan kontrol.

Tabel 1. Hasil pretest dan posttest kelas kontrol.

\begin{tabular}{lcccc}
\hline & Jlh & Min & Maks & Rata-rata \\
\hline Pretest & 20 & 40 & 75 & 59,00 \\
Posttest & 20 & 60 & 90 & 72,75 \\
\hline
\end{tabular}

Berdasarkan tabel diatas dapat dilihat bahwa nilai pretest adalah 59 sedangkan nilai posttest adalah 72,75. Hal ini menunjukkan peningkatan pemahaman konsep siswa terhadap materi alat-alat optik naik menjadi 13,75 .

Tabel 2. Hasil uji normalitas pretes kelas kontrol dan pretes eksperimen.

\begin{tabular}{llccc}
\hline \multirow{2}{*}{ Kasil pemahaman konsep } & \multicolumn{3}{c}{ Shapiro-Wilk } \\
& \multicolumn{1}{c}{ Statistik } & Df & Sig. \\
\cline { 2 - 5 } & Pretes kelas kontrol & 0,924 & 20 & 0,120 \\
& Pretes kelas eksperimen & 0,969 & 20 & 0,729 \\
\hline
\end{tabular}

Berdasarkan tabel diatas nilai siginifikan pretest kelas kontrol 0,120>0,05 dan nilai signifikan pretest kelas eksperimen 0,729 >0,05. Sehingga dapat disimpulkan bahwa kedua data terdistribusi normal.

Tabel 3. Hasil uji homogenitas pretest kelas kontrol dan kelas eksperimen.

\begin{tabular}{lcccc}
\hline & $\begin{array}{c}\text { Retribusi } \\
\text { Statistik }\end{array}$ & df1 & df2 & Sig. \\
\hline Based on mean & 0,761 & 1 & 38 & 0,389 \\
Based on median & 0,891 & 1 & 38 & 0,351 \\
Based on median and witf adjusted df & 0,891 & 1 & 37,532 & 0,351 \\
Based on trimmed mean & 0,789 & 1 & 38 & 0,382 \\
\hline
\end{tabular}

Berdasarkan tabel diatas nilai signifikan hasil uji homogenitas adalah $>0,05$. Sehingga dapat disimpulkan bahwa kedua data terdistribusi homogen.

Tabel 4. Hasil uji hipotesis pretest kelas kontrol dan pretest kelas eksperimen.

\section{Equality of Variances}

\begin{tabular}{|c|c|c|c|c|c|c|c|c|}
\hline & \multicolumn{3}{|c|}{ Equality of Variances } & \multicolumn{5}{|c|}{ t-test for Equality of Means } \\
\hline & \multirow{2}{*}{$\mathbf{t}$} & \multirow{2}{*}{ Df } & \multirow{2}{*}{ Sig } & \multirow[t]{2}{*}{$\begin{array}{l}\text { Sig. (2- } \\
\text { tailed) }\end{array}$} & \multirow[t]{2}{*}{$\begin{array}{c}\text { Mean } \\
\text { Differen } \\
\text { ce }\end{array}$} & \multirow{2}{*}{$\begin{array}{l}\text { Std. } \\
\text { Error } \\
\text { Differe } \\
\text { nce }\end{array}$} & \multicolumn{2}{|c|}{$\begin{array}{c}\text { 95\% Confidence } \\
\text { Interval the } \\
\text { Difference }\end{array}$} \\
\hline & & & & & & & Lower & Upper \\
\hline $\begin{array}{l}\text { Equal } \\
\text { variances } \\
\text { assumed }\end{array}$ & 1,972 & 38 & 0,389 & 0,056 & 7,050 & 3,574 & $-0,186$ & 14,286 \\
\hline $\begin{array}{l}\text { Equal } \\
\text { variances } \\
\text { not assumed }\end{array}$ & 1,972 & 36,751 & - & 0,056 & 7,050 & 3,574 & $-0,194$ & 14,294 \\
\hline
\end{tabular}

Berdasarkan tabel di atas pada uji Equal variances assumed kedua nilai signifikan yang diperoleh adalah $0,389>0.05$. Sehingga dapat disimpulkan bahwa kedua nilai siginifikan tersebut 
diterima. Hal ini berarti bahwa siswa pada kedua kelas memiliki pemahaman awal yang sama pada konsep materi alat-alat optik.

Tabel 5. Hasil pretest dan posttest Kelas Eksperimen

\begin{tabular}{lcccc}
\hline & Jlh & Min & Maks & Rata-rata \\
Pretest & 20 & 25 & 74 & 51,95 \\
Posttest & 20 & 85 & 95 & 86,75 \\
\hline
\end{tabular}

Berdasarkan tabel diatas dapat diketahui bahwa terjadi peningkatan pemahaman konsep siswa pada kelas eksperimen. Hal ini dapat dilihat melalui nilai rata-rata yang diperoleh siswa pada saat uji pretest dan posttest.

Tabel 6. Hasil uji normalitas posttest kelas kontrol dan posttest eksperimen.

\begin{tabular}{|c|c|c|c|c|}
\hline \multirow{3}{*}{ Hasil pemahaman konsep } & \multirow{2}{*}{ Kelas } & \multicolumn{3}{|c|}{ Shapiro-Wilk } \\
\hline & & Statistik & Df & Sig. \\
\hline & Posttest kelas control & 0,924 & 20 & 0,121 \\
\hline & Posttest kelas eksperimen & 0,632 & 20 & 0,000 \\
\hline
\end{tabular}

Berdasarkan tabel 6 nilai signifikan posttest kelas kontrol 0,121>0,05 sehingga dapat disimpulkan bahwa data tersebut berdistribusi normal. Sedangkan nilai signifikan posttest kelas eksperimen $0,000<$ 0,05 sehingga dapat disimpulkan bahwa data tersebut tidak normal.

Tabel 7. Hasil uji homogenitas posttest kelas kontrol dan kelas eksperimen.

\begin{tabular}{cccc}
\hline Levene Statistic & df1 & df2 & Sig. \\
\hline 13,343 & 1 & 38 & 0,001 \\
\hline
\end{tabular}

Berdasarkan tabel 7 nilai signifikan hasil data posttest kelas kontrol dan eksperimen 0,001 < 0,05. Sehingga dapat disimpulkan bahwa data tersebut tidak homogen.

Tabel 8. Hasil uji hipotesis posttest kelas kontrol dan posttest kelas eksperimen.

\begin{tabular}{ll}
\hline & Hasil Pemahaman Konsep \\
\hline Mann-Whitney $U$ & 37,500 \\
Wilcoxon $W$ & 247,500 \\
$Z$ & $-4,599$ \\
Asymp. Sig. (2 tailed) & 0,000 \\
\hline
\end{tabular}

Berdasarkan tabel diatas bahwa nilai Asymp. Sig. (2 tailed) sebesar 0,000<0,05. Maka dapat disimpulkan bahwa hipotesis diterima. Dengan demikian dapat dikatakan bahwa terdapat peningkatan pemahaman siswa pada konsep materi alat-alat optik dengan penerapan model TGT melalui simulasi PhET di MAN 3 Aceh Utara kelas XI.

\section{Pembahasan}

Penelitian ini bertujuan untuk mengetahui apakah media simulasi PhET (Physics Education Technology) dapat meningkatkan pemahaman siswa/i pada materi alat-alat optik di kelas XI MIA MAN 3 Aceh Utara.Penelitian ini dilakukan dengan menggunakan instrumen tes berupa 20 soal yang terdiri dari dua tipe yaituu pretest dan posttest . Dimana soal pretest dan posttest memiliki kesamaan. Peneliti ini menggunakan dua kelas, dimana kelas XI MIA 2 sebagai kontrol sedangkan kelas XI MIA 3 sebagai kelas eksperimen. Kelas XI MIA 3 mendapatkan perlakuan dengan model TGT (Teams 
Games Turnament) melalui simulasi PhET, selain itu LKS (Lembar Kerja Siswa) digunakan sebagai sarana pendukung proses pembelajaran berlangsung. Sedangkan untuk kelas XI MIA 2 merupakan kelas yang mendapatkan perlakuan dengan menggunakan model pembelajaran konvesional dan peneliti disini menggunakan model pembelajaran Direct Intruction.

Berdasakan hasil uji pretest dan posttest pada kelas eksperimen dan kelas kontrol dapat diketahui bahwa peningkatan rata-rata hasil pemahaman konsep pada materi alat-alat optik lebih tinggi untuk kelas ekpserimen daripada kelas kontrol. Hal ini menunjukkan bahwa terdapat pengaruh terhadap perlakuan yang diberikan pada masing-masing kelas. Kelas eksperimen memiliki peningkatan rata-rata hasil pemahaman konsep siswa lebih tinggi, hal ini dikarenakan pada proses pembelajaran menggunakan model TGT (Teams Games Tournament) melalui simulasi PhET. Sedangkan pada kelas kontrol memilik peningkatan rata-rata hasil pemahaman konsep lebih rendah daripada kelas eksperimen dikarenakan menggunakan model konvesional yaitu Direct Intruction.

Penggunaan model TGT melalui simulasi PhET tidak hanya berdampak terhadap peningkatan pemahaman konsep siswa saja, tetapi juga berdampak terhadap proses pembelajaran berlangsung. Pada proses pembelajaran menggunakan model TGT melalui simulasi PhET kondisi kelas siswa lebih semangat dalam proses pembelajaran berlangsung. Siswa juga lebih antusias, tidak ngantuk, tidak tertekan dan siswa mengaku lebih mudah memahami konsep fisika terutama materi alat-alat optik. Hal ini dikarenakan siswa dapat melihat langsung kondisi pada simulasi PhET.

Sedangkan proses pembelajaran pada kelas kontrol yang menggunakan model konvensional cenderung tidak aktif. Selain itu siswa merasa tertekan dan terbebani dikarenakan pembelajaran hanya terfokus pada papan tulis tanpa ada media pendukung lainnya. Siswa juga merasa sulit untuk memahami pelajaran fisika terutama pada materi alat-alat optik. Hal ini dikarenakan siswa harus menggunakan imajinasi atau berkhayal untuk menyelasaikan suatu permasalahan atupun untuk memahami suatu konsep.

Pada saat uji pretest diperoleh rata-rata hasil pemahaman konsep siswa kelas eksperimen sebesar 51,95 dan rata-rata hasil pemahaman konsep siswa pada saat uji posttest kelas eksperimen sebesar 86,75. Dengan demikian dapat dilihat terjadi peningkatan rata-rata pemahaman konsep siswa kelas eksperimen sebesar 34,8. Sedangkan pada kelas kontrol diperoleh rata-rata hasil pemahaman konsep siswa pada saat pretest sebesar 59 dan rata-rata hasil pemahaman konsep siswa pada saat posttest sebesar 72,75. Dengan demikian peningkatan rata-rata pemahaman konsep siswa pada kelas kontrol sebesar 13,75.

Adapun peningkatan pemahaman konsep siswa menggunkan model TGT melalui simulasi PhET pada materi alat-alat optik dikelas XI pada kelas kontrol adalah $44 \%$ sedangkan untuk kelas eksperimen adalah $80 \%$.

Berdasarkan hasil penelitian dan pembahasan diatas, dari ketuntasan hasil belajar siswa dalam pemahaman konsep pada kegiatan pembelajaran siswa terhadap pembelajaran, maka dapat disimpulkan bahwa menggunakan model pembelajaran TGT melalui simulasi PhET pada materi alat-alat optik di MAN 3 Aceh Utara efektif digunakan dalam proses pembelajaran.

\section{PENUTUP}

Berdasarkan data penelitian yang diperoleh dari hasil analisa data dan pengujian hipotesis, maka dapat disimpulkan bahwa: Nilai rata-rata hasil pemahaman siswa pada konsep materi alat-alat optik pada kelas eksperimen dengan model pembelajaran TGT melalui simulasi PhET adalah 86,75. Sedangkan untuk nilai rata-rata hasil pemahaman siswa pada konsep materi alat-alat optik pada kelas kontrol dengan model pembelajaran TGT melalui simulasi PhET adalah 72,75. (2) Nilai uji hipotesis pretest kelas kontrol dan eksperimen pada uji equal variances assumed adalah 0,389>0,05, maka dapat disimpulkan nilai signifikan tersebut diterima. Sedangkan nilai uji hipotesis posttest kelas kontrol dan eksperimen dihitung menggunakan uji mann-whitney test adalah $0,000<0,05$, maka dapat disimpulkan bahwa hipotesis diterima. (3) Peningkatan pemahaman siswa pada konsep materi alat-alat 
optik di MAN 3 Aceh Utara kelas XI lebih baik menggunakan model TGT melalui simulasi PhET dibandingkan hanya menggunakan model pembelajaran konvesional (direct intruction). (4) Nilai NGain yang diperoleh kelas kontrol adalah 44\%. Sedangkan nilai N-Gain yang diperoleh kelas eksperimen adalah $80 \%$. Sehingga dapat disimpulkan bahwa nilai N-Gain kelas kontrol lebih rendah dibandingkan nilai N-Gain pada kelas eksperimen.

\section{DAFTAR PUSTAKA}

Choiron, M. (2013). Memafaatkan media ICT dalam pembelajaran (Online):(htttp://www.technology.kompasiana.com/terapan/2013/11/28/memanfaatkan mediapembelajaran, 68 .

Ekawati, y., Haris, A., \& Amin, H. B. (2017). Penerapan Media Simulasi Menggunakan PHET (Physics Education And Technology) Terhadap Hasil Belajar Fisika Peserta Didik Kelas X SMA Muhammadiyah Limbung . jurnal pendidikan Fisika Universitas Muhammaddiyah Makassar, 77.

Ekocin. (2011). Model pembelajaran Teams games turnament . jakarta: PT rineka Cipta.

Finkelstein, N. (2006). Hightech Tools For Teaching Physics: The Physics Education Technology Project. Merlot journal of of online learning and teaching , 110-121.

Hadiwiyanti, I. (2015). Analisis Kemampuan Pemahaman Konsep Siswa untuk mengukur kemampuan siswa . Jakarta: Bumi Aksara.

Hamzah B, u. (2007). Profesi kependidikan, problema,solusi,dan reformasi pendidikan di Indonesia. Jakarta: Bumi Aksara.

Imas, \& Kurniasih. (2012). penerapan model pembelajaran kooperatif TGT. SAP , 47-48.

jacobsen, A., D, p. E., \& Donald, K. (2009). methods for teaching. yogyakarta: pustaka pengajar.

Kusumandari, e. (2011). penerapan pembelajaran kooperatif tgt. SAP, 48.

Lailiyah, E. (2009). Perbandingan efektivitas metode javascript terhadap demostrasi dan ceramah dalam meningkatkan kemampuan siswa untuk materi pemuaian dan wujud zat. jurnal pembelajaran fisika sekolah menengah, 9-13.

Malik, N. (2010). Pengaruh strategi pembelajaran interaktif model simulasi mata kuliah rangkaian listrik terhadap hasil belajar mahasiswa program studi pendidikan teknik elektro FTUNM. Jurnal MEDTEK , 23.

Musfiqon. (2012). pengembangan media dan sumber pembelajaran. jakarta: PT prestasi pustaka karya.

Siahaan, s. m. (2012). penggunaan teknologi informasi dan komunikasi dalam pembelajaran fisika. palembang: Universitas Sriwijaya.

Slavin. (2007). Kooperatif learning: riset dan praktik. jurnal ilmiah sekolah dasar , 166-167.

Sudha, I. K., \& gading, n. t. (2016). Pengaruh model pembelajaran Teams games tournament dan motivasi berprestasi terhadap hasil belajar IPS kelas VI. e-journal PGSD universitas pendidikan ganesha jurusan PGSD , 45. 
Susilo, M. (2010). Menjadi guru profesional siapa takut. Yogyakarta: lentera pustaka.

Umar. (2013). Media pendidikan: peran dan fungsinya dalam pembelajaran. Jurnal Tarbawiyah , 135. 